\title{
Post-transplantation diabetes mellitus after kidney transplantation and its related factors in Iranian patients: a retrospective single-center study
}

\author{
Elham Ramezanzadeh ${ }^{\circledR}$, Azin Tirbakhsh ${ }^{\circledR}$, Ali Monfared ${ }^{\circledR}$, Masoud Khosravi* ${ }^{\circledR}$, Mohammadkazem \\ Lebadi $^{\circledR}$, Behrang Motamed ${ }^{\circledR}$, Gholamreza Mokhtari ${ }^{\circledR}$, Ehsan Kazemnezhad Leyli ${ }^{\circledR}$ \\ Razi Clinical Research Development Center, School of Medicine, Razi hospital, Guilan University of Medical Sciences, Rasht, Iran
}

\section{A R T I C L E I N F O}

Article Type:

Original

\section{Article History:}

Received: 3 August 2020

Accepted: 15 October 2020

ePublished: 23 November 2020

\section{Keywords:}

Ciclosporin,

Immunosuppression,

Post-transplantation diabetes mellitus, Renal transplantation, Tacrolimus

\begin{abstract}
A B S T R A C T
Introduction: Post-transplantation diabetes mellitus (PTDM) is a metabolic complication following transplantation, which is associated with cardiovascular disease and leads to increased post-ttransplantation morbidity and mortality.

Objectives: To identify the incidence of PTDM and its risk factors in kidney recipients at a single-center in Iran.

Patients and Methods: This retrospective study was conducted on 379 kidney recipients with a negative history of diabetes mellitus who underwent transplant before January 2017. PTDM was defined according to the diagnostic criteria of the American Diabetes Association (ADA) and the World Health Organization (WHO). Data on demographic, clinical characteristics and laboratory parameters were collected. Kaplan-Mayer analysis was used to evaluate the cumulative incidence of PTDM. The association between risk factors and PTDM incidence was identified with stepwise Cox regression.

Results: The cumulative incidence of PTDM during a 24-month follow-up was 30.1\% (95\% CI: 25.6-34.8). By univariate analysis, modifiable or non-modifiable risk factors for PTDM development included recipient age, body mass index (BMI), marital status, family history of diabetes, smoking, type of transplant, hepatitis $\mathrm{C}$ virus (HCV), cytomegalovirus (CMV), transplant rejection, TG, tacrolimus, cyclosporine and beta blocker. In this study, family history of diabetes, type of transplant, HCV, CMV, TG, tacrolimus, and beta blocker were predictors of development of PTDM in Cox proportional hazard models.

Conclusion: The incidence of PTDM was high. Identification of risk factors determines appropriate strategies for PTDM incidence risk reduction.
\end{abstract}

Implication for health policy/practice/research/medical education:

This research is an implication for health policy because diabetes mellitus and its complication can impose a huge economic and social burden on governments and people.

Please cite this paper as: Ramezanzadeh E, Tirbakhsh A, Monfared A, Khosravi M, Lebadi MK, Motamed B, Mokhtari G, Kazemnezhad Leyli E. Post-transplantation diabetes mellitus after kidney transplantation and its related factors in Iranian patients: a retrospective single-center study. J Renal Inj Prev. 2021; 10(2): e14. doi: 10.34172/jrip.2021.14.

\section{Introduction}

Dialysis therapy and kidney transplantation are treatments for patients with end-stage renal disease (ESRD). Renal transplantation is an effective treatment method associated with a higher quality of life and better patient survival in these people $(1,2)$.

In recent decades, significant progress has been made regarding the short-term complications of kidney transplantation such as delayed kidney function and acute rejection, but a proportional advancement in long-term outcomes, including cardiovascular deaths, infectious and malignant causes, was not observed (3-5). PTDM is one of the metabolic complications of transplantation that is life threatening, because older patients and those with diabetes are at higher risk of cardiovascular disease and infections (3,6-8). At the international consensus meeting in 2013, guidelines for the diagnosis and management of PTDM were updated and advocated the World Health 
Organization (WHO) and the American Diabetes Association (ADA) criteria for the diagnosis of diabetes mellitus (DM) and impaired glucose tolerance (IGT) (9).

The prevalence of PTDM in various studies depends on the duration of follow-up, diagnostic criteria, as well as the immunosuppressive regimen used after transplantation. This type of diabetes mostly occurs within 6 months of transplantation. The six months after transplantation, the annual incidence of diabetes is similar to those on the waiting list (10).

Risk factors for PTDM are the same as those for type 2 diabetes, but additional transplant related factors include immunosuppression (especially glucocorticoids and calcineurin inhibitors) and infection (hepatitis C [HCV] and cytomegalovirus [CMV]) (11).

Transplant patients are very vulnerable. PTDM, like other metabolic diseases, can increase the cost of treatment. This problem puts a huge financial burden on the health system.

\section{Objectives}

Due to few similar studies on the incidence of PTDM and the risk factors affecting it in Iran, we conducted this study to evaluate it in patients who underwent kidney transplantation at Razi hospital in Rasht.

\section{Patients and Methods \\ Study design}

This is a retrospective cross-sectional study conducted on renal recipients who transplanted before 2017 at the Razi hospital (renal transplant center of Guilan, Iran).

Regarding ADA and WHO definition for PTDM we defined it as a fasting plasma glucose of at least $126 \mathrm{mg} / \mathrm{dL}$ or random plasma glucose equal to or greater than $200 \mathrm{mg} /$ $\mathrm{dL}$, more than 2 weeks with persistent hyperglycemia, or the necessity of hypoglycemic drugs after transplantation) (12).

Patients with multiple organ transplants, second transplantation, history of diabetes mellitus before ESRD, follow up period $<24$ months, and incomplete records were excluded.

Minimum sample size, according to the formula, was estimated to be 360 renal recipients based on the study of Kasiske et al in which, relative risk PTDM based on body mass index (BMI) was 1.73 (7), with a 95\% confidence interval, $90 \%$ test power. The sampling method was based on kidney recipients from new to old. Data were extracted from patients' clinical records and the transplant center clinical records.

Variables including donor type (living or deceased), donor gender, and for recipients including age, gender, marital status, education, occupation, smoking, family history of diabetes, BMI, etiology of ESRD, HCV, CMV transplant, TG, LDL-c, uric acid, tacrolimus, cyclosporine, sirolimus, prednisolone, cellcept, atorvastatin and betablocker were collected.

\section{Ethical issues}

The research followed the tenets of the Declaration of Helsinki. This study was approved by the Guilan University of Medical Sciences Ethics Committee (No. IR.GUMS. REC.1398.098). Informed consent was obtained from patients. This study was extracted from M.D thesis of Azin Tirbakhsh at this university (Thesis\# 1100).

\section{Data analysis}

Demographic, clinical and laboratory characteristics of kidney recipients with PTDM were compared with those non-PTDM, to investigate the incidence of PTDM and find out various risk factors associated with it. Univariate analysis of factors associated with PTDM was performed with chi-square test for categorical variables and independent $t$ test and Mann-Whitney $U$ test for continuous variables, respectively. The independent association between the factors and development of PTDM in the second year after discharge was examined using stepwise Cox regression. Survival free to onset of PTDM was illustrated using Kaplan-Meier survival curves. All analyses were performed using SPSS 16.0 TM (SPSS Inc., Chicago, IL). Statistical significance for comparisons was defined as $P<0.05$.

Results

In this study, 379 patients who underwent kidney transplantation in Razi hospital in Rasht before 2017 were selected and evaluated for developing PTDM and also the factors affecting it. These patients were followed for 24 months, 114 developed PTDM, and 265 out of a total of patients showed no evidence of diabetes. Out of 265 non-PTDM patients, 11 (4.2\%) people developed blood glucose disorders during these 24 months, which were transient and resolved without treatment.

In our study, the cumulative incidence of NODAT during a 24 -month follow-up was $30.1 \%$. This amount at $1,3,6$ and 12 months were $16.1 \%, 20.3 \%, 27.5 \%$ and $29.0 \%$, respectively. This finding shows that the highest incidence was during the first year (Table 1).

Recipients' gender, education, occupation, etiology of ESRD, LDL-c, uric acid, donor's gender, use of sirolimus, and atorvastatin had no significant difference between two groups $(P>0.05)$. Married recipients $(P=0.004)$, family history of diabetes $(P<0.001)$, smoking $(P<0.001)$, $\mathrm{HCV}$ infection $(P<0.001)$, cytomegalovirus (CMV) infection $(P=0.001)$, transplant rejection $(P<0.001)$, deceased donor $(P<0.001)$, administration of tacrolimus

Table 1. Incidence of PTDM in kidney transplant recipients

\begin{tabular}{llcc}
\hline \multirow{2}{*}{ PTDM } & \multirow{2}{*}{ Count } & \multicolumn{2}{c}{$95 \% \mathrm{Cl}$} \\
\cline { 3 - 4 } & & Lower & Upper \\
\hline Yes & $114(30.1)$ & 25.6 & 34.8 \\
No & $265(69.9)$ & 65.2 & 74.4 \\
Total & $379(100.0)$ & - & - \\
\hline
\end{tabular}


$(P=0.002)$ and beta blocker $(P=0.030)$, and recipients' age $(P=0.001)$, BMI $(P=0.001)$, and TG $(P=0.006)$ are significantly higher in PTDM group (Tables 2 and 3).

Around $28.9 \%$ of PTDM occurred within the first month after transplantation. More than $50 \%$ occurred under two months and over three-quarters of the cases (76.3\%) occurred during the first three months after transplantation (Table 4).

The disease-free survival rates of the patients in the 1st, $3 \mathrm{rd}, 6$ th, 12th, and 24th months were $91.3 \pm 1.4,79.7 \pm 2.1$,

Table 2. Demographic and laboratory parameters in PTDM and non- PTDM kidney transplant Recipients

\begin{tabular}{|c|c|c|c|c|}
\hline Parameter & Missing data & PTDM $(n=114)$ & Non- PTDM (n=265) & $P$ value \\
\hline Recipient age, $y$ & $0(0)$ & $44.2 \pm 13.9$ & $39.2 \pm 13.4$ & $0.001^{\mathrm{a}}$ \\
\hline Recipient BMI, kg/m² & $0(0)$ & $26.6 \pm 5.4$ & $24.9 \pm 4.6$ & $0.001^{\mathrm{a}}$ \\
\hline Recipient sex & $0(0)$ & & & \multirow{3}{*}{$0.536^{c}$} \\
\hline Male & & $58(28.7)$ & $144(71.3)$ & \\
\hline Female & & $56(31.6)$ & $121(68.4)$ & \\
\hline Marital status & 47 (12.4) & & & \multirow{3}{*}{$0.004^{c}$} \\
\hline Married & & $77(34.5)$ & $146(65.5)$ & \\
\hline Single & & $21(19.3)$ & $88(80.7)$ & \\
\hline Education & $34(9.0)$ & & & \multirow{4}{*}{$0.853^{c}$} \\
\hline High school & & $46(29.7)$ & $109(70.3)$ & \\
\hline Diploma & & $26(26.8)$ & $71(73.2)$ & \\
\hline College \& post-college & & $28(30.1)$ & 65 (69.9) & \\
\hline Occupation & $91(24.0)$ & & & \multirow{7}{*}{$0.992^{c}$} \\
\hline Farmer & & $5(33.3)$ & $10(66.7)$ & \\
\hline Student & & $6(33.3)$ & $12(66.7)$ & \\
\hline Employee & & $21(31.3)$ & $46(68.7)$ & \\
\hline Self-employed & & $27(30.0)$ & $63(70.0)$ & \\
\hline Housewife & & $26(29.2)$ & $63(70.8)$ & \\
\hline Unemployed & & $2(22.2)$ & $7(77.8)$ & \\
\hline Family history of diabetes & $26(6.9)$ & & & \multirow{3}{*}{$<0.001^{\mathrm{c}}$} \\
\hline Yes & & $70(52.2)$ & $64(47.8)$ & \\
\hline No & & $35(16.0)$ & $184(84.0)$ & \\
\hline Smoking & $0(0)$ & & & \multirow{3}{*}{$<0.001^{c}$} \\
\hline Yes & & 39 (54.9) & $32(45.1)$ & \\
\hline No & & $75(24.4)$ & $233(75.6)$ & \\
\hline Cause of ESRD & $0(0)$ & & & \multirow{7}{*}{$0.466^{c}$} \\
\hline Hypertension & & $27(36.5)$ & $47(63.5)$ & \\
\hline ADPKD & & $13(39.4)$ & $20(60.6)$ & \\
\hline Urological & & $16(32.0)$ & $34(68.0)$ & \\
\hline GN & & $24(30.4)$ & $55(69.6)$ & \\
\hline Other & & $28(23.5)$ & $82(76.5)$ & \\
\hline Unknown & & $6(25.0)$ & $18(75.0)$ & \\
\hline Donor type & $42(11.1)$ & & & \multirow{3}{*}{$<0.001^{c}$} \\
\hline Alive & & $53(22.3)$ & $185(77.7)$ & \\
\hline Deceased & & $45(45.5)$ & $54(54.5)$ & \\
\hline Donor sex & 67 (17.7) & & & \multirow{3}{*}{$0.395^{c}$} \\
\hline Male & & $69(29.5)$ & $165(70.5)$ & \\
\hline Female & & $27(34.6)$ & $51(65.4)$ & \\
\hline $\mathrm{HCV}$ & $7(1.8)$ & & & \multirow{3}{*}{$<0.001^{c}$} \\
\hline Positive & & $25(73.5)$ & $9(26.5)$ & \\
\hline Negative & & $87(25.7)$ & $251(74.3)$ & \\
\hline CMV & $25(6.6)$ & & & \multirow{3}{*}{$0.001^{c}$} \\
\hline Positive & & $46(41.8)$ & $64(58.2)$ & \\
\hline Negative & & $61(25.0)$ & $183(75.0)$ & \\
\hline Transplant rejection & $28(7.4)$ & & & \multirow{3}{*}{$<0.001^{\mathrm{c}}$} \\
\hline Yes & & $56(50.9)$ & $54(49.1)$ & \\
\hline No & & $57(23.7)$ & $184(76.3)$ & \\
\hline LDL-c & 212 (55.9) & $118.2 \pm 83.2$ & $94.9 \pm 38.5$ & $0.737^{b}$ \\
\hline TG & 145 (38.3) & $196.9 \pm 127.8$ & $150.5 \pm 75.4$ & $0.006^{b}$ \\
\hline Uric acid & $194(51.2)$ & $8.0 \pm 10.4$ & $6.9 \pm 5.1$ & $0.644^{\mathrm{b}}$ \\
\hline
\end{tabular}

${ }^{\mathrm{a}}$ Independent $t$ test, ${ }^{\mathrm{b}}$ Mann-Whitney test, ${ }^{\mathrm{c}}$ Chi-square test. 
Table 3. Immunosuppression used in PTDM and non- PTDM kidney transplant recipients

\begin{tabular}{|c|c|c|c|c|}
\hline Immunosuppression & Missing data & PTDM (n=114) & Non- PTDM (n=265) & $P$ value \\
\hline Tacrolimus & $15(4.0)$ & & & \multirow{3}{*}{$0.002^{\mathrm{a}}$} \\
\hline Yes & & $50(41.3)$ & $71(58.7)$ & \\
\hline No & & $61(25.1)$ & $182(74.9)$ & \\
\hline Cyclosporine & $11(2.9)$ & & & \multirow{3}{*}{$<0.001^{\mathrm{a}}$} \\
\hline Yes & & $41(20.7)$ & $157(79.3)$ & \\
\hline No & & $71(41.8)$ & $99(58.2)$ & \\
\hline Sirolimus & $15(4.0)$ & & & \multirow{3}{*}{$0.103^{a}$} \\
\hline Yes & & 25 (39.7) & $38(60.3)$ & \\
\hline No & & $88(29.2)$ & $213(70.8)$ & \\
\hline Cellcept & $6(1.6)$ & & & \multirow{3}{*}{$<0.001^{\mathrm{a}}$} \\
\hline Yes & & $66(28.3)$ & $167(71.7)$ & \\
\hline No & & $48(34.3)$ & $92(65.7)$ & \\
\hline Atorvastatin & $8(2.1)$ & & & \multirow{3}{*}{$0.297^{a}$} \\
\hline Yes & & $60(28.3)$ & $152(71.7)$ & \\
\hline No & & $53(33.3)$ & $106(66.7)$ & \\
\hline Beta blocker & $18(4.7)$ & & & \multirow{3}{*}{$0.030^{\mathrm{a}}$} \\
\hline Yes & & $19(45.2)$ & $23(54.8)$ & \\
\hline No & & $92(28.8)$ & $227(71.2)$ & \\
\hline Prednisolone & $1(0.3)$ & & & \multirow{3}{*}{$0.366^{\mathrm{a}}$} \\
\hline Yes & & $107(30.5)$ & $244(69.5)$ & \\
\hline No & & $6(22.2)$ & $21(77.8)$ & \\
\hline
\end{tabular}

${ }^{a}$ Chi-square test.

$72.5 \pm 2.3,70.9 \pm 2.3$, and $69.8 \pm 2.4$, respectively, according to the Kaplan-Meyer plot (Figure 1).

Multivariate Cox regression model confirmed the independent risk factors were; family history of diabetes $(\mathrm{HR}=2.240,95 \% \mathrm{CI}: 1.020-4.920)$, donor type $(\mathrm{HR}=2.370$, 95\% CI: $1.064-5.281)$, TG $(\mathrm{HR}=1.005$, 95\% CI: $1.001-$ 1.010), $\mathrm{HCV}(\mathrm{HR}=3.946,95 \% \mathrm{CI}: 1.095-14.226), \mathrm{CMV}$ $(\mathrm{HR}=2.910,95 \% \quad \mathrm{CI}:$ 1.147-7.383), tacrolimus use $(\mathrm{HR}=2.464,95 \% \mathrm{CI}: 1.179-5.148)$, and beta blocker use $(\mathrm{HR}=5.577,95 \% \mathrm{CI}: 1.868-16.652$; Table 5).

\section{Discussion}

PTDM is a common and important metabolic complication of renal transplantation (6-8). In our study, the cumulative incidence of PTDM during a 24-month follow-up was $30.1 \%$. This amount at $1,3,6$ and 12 months were $16.1 \%$,

Table 4. Cumulative incidence of PTDM within 24 months kidney transplant recipients

\begin{tabular}{lccc}
\hline PTDM incidence time (mon) & No. & $\%$ & Cumulative percent \\
\hline 0.25 & 12 & 10.5 & 10.5 \\
0.50 & 3 & 2.6 & 13.2 \\
0.75 & 18 & 15.8 & 28.9 \\
1.0 & 28 & 24.6 & 53.5 \\
2.0 & 16 & 14.0 & 67.5 \\
3.0 & 10 & 8.8 & 76.3 \\
4.0 & 15 & 13.2 & 89.5 \\
5.0 & 2 & 1.8 & 91.2 \\
6.0 & 6 & 5.3 & 96.5 \\
12.0 & 4 & 3.5 & 100.0 \\
Total & 114 & 100.0 & \\
\hline
\end{tabular}

$20.3 \%, 27.5 \%$ and $29.0 \%$, respectively. This finding shows that the highest incidence was during the first year. Recent studies reported that $4 \%-30 \%$ of patients will develop PTDM within the first year post-transplant $(6,12,13)$. According to Kasiske et al study, the cumulative incidence of PTDM was $9.1 \%, 16.0 \%$, and $24.0 \%$ at 3,12 , and 36 months post-transplant, respectively (7). This discrepancy in findings can be due to multifactor such as criterion for diagnostic of DM, follow-up period, variability in the types and amounts of immunosuppression used, and the presence of pre-transplant risk factors.

PTDM risk factors are categorized into two groups of non-modifiable and modifiable risk factors. Non-

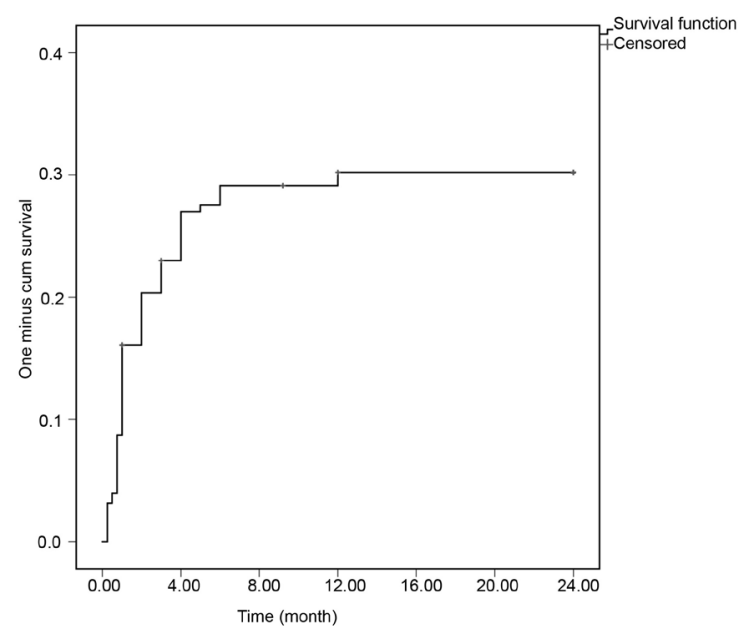

Figure 1. Kaplan-Meier curve estimating the survival free from PTDM. 
Table 5. Adjusted hazard ratios for PTDM after transplantation

\begin{tabular}{|c|c|c|c|c|c|c|}
\hline \multirow{2}{*}{ Variables } & \multirow{2}{*}{ B } & \multirow{2}{*}{ SE } & \multirow{2}{*}{$P$ value } & \multirow{2}{*}{ Adjusted HR } & \multicolumn{2}{|c|}{$95.0 \% \mathrm{Cl}$ for $\mathrm{HR}$} \\
\hline & & & & & Lower & Upper \\
\hline Family history of diabetes (yes/no) & 0.806 & 0.401 & 0.045 & 2.240 & 1.020 & 4.920 \\
\hline TG & 0.005 & 0.002 & 0.020 & 1.005 & 1.001 & 1.010 \\
\hline Donor type (deceased/alive) & 0.863 & 0.409 & 0.035 & 2.370 & 1.064 & 5.281 \\
\hline HCV (yes/no) & 1.373 & 0.654 & 0.036 & 3.946 & 1.095 & 14.226 \\
\hline CMV (yes/no) & 1.068 & 0.475 & 0.024 & 2.910 & 1.147 & 7.383 \\
\hline Tacrolimus (yes/no) & 0.902 & 0.376 & 0.016 & 2.464 & 1.179 & 5.148 \\
\hline Beta blocker (yes/no) & 1.719 & 0.558 & 0.002 & 5.577 & 1.868 & 16.652 \\
\hline
\end{tabular}

modifiable risk factors include advanced age, gender, ethnicity, genetic background, a positive family history of DM, Pre-diabetes, and underlying kidney disease. All of these risk factors can usually be identified before transplantation. There are many risk factors for PTDM that may be considered modifiable, at least on a theoretical basis. Some of these risk factors include obesity, immunosuppressive therapies (e.g., tacrolimus, cyclosporine and corticosteroid), infectious agents (e.g., $\mathrm{BK}$ virus, $\mathrm{HCV}$ and $\mathrm{CMV}$ ), and hypomagnesaemia after transplant $(12,14-17)$.

The results of current study showed that the highest percentage of PTDM was in the age group of 50 years and above (40.38\%). In univariate analysis, age was an influential factor, but in multivariate analysis, this factor was not significant.

In the majority of studies, older age has been identified as the strongest and most important risk factor for PTDM $(7,18,19)$. In the study by Cosio et al, recipients older than 45 years old were 2.9 times more likely to become PTDM than younger recipients. In addition, age increased the risk for development of PTDM 1.5-fold for every 10-year increase in age (20).

Based on the findings of the present study, there is no statistically significant relationship between the gender of recipients and the gender of donors with the incidence of PTDM, which is consistent with previous studies $(20,21)$. However, in some studies, the male donor was a risk factor for PTDM (7).

We found that renal recipients with a history of smoking were two-fold more likely to develop PTDM, but this relationship did not confirm in multivariate analysis, while in the study by Santos et al, the multivariate analysis identified smoking habit as an independent risk factor for PTDM (21). On other hand, Dedinska et al showed that smoking is not a risk factor for developing PTDM (22). The lack of significance in our study may be due to the absence of accurate data about smoking history and inattention to passive smokers.

There was no significant relationship between education and occupation of kidney recipients with the development of PTDM. Additionally, the incidence of PTDM in married people was significantly higher than single people (34.5 versus $19.3 \%$ ). Because the age variable is in multivariate analysis, marital status after entering the analysis lost its significance because married patients were probably older. Unfortunately, we did not have patients' pre-transplant weight, and only the post-transplant BMI was recorded.

The incidence of PTDM in obese people with a BMI above 30 was equal to $44.2 \%$ and was more than other groups. BMI was considered as a significant index in univariate analysis. In most studies, weight and BMI have been associated with PTDM $(7,18,20,23)$. In addition to obesity, overweight people (BMI between 25 and $30 \mathrm{~kg} /$ $\mathrm{m}^{2}$ ) also have a higher risk of developing diabetes (18). Obese people with IGT test reduced the risk of type 2 diabetes mellitus significantly (from 23\% to 11\%) with life style modification (24). Therefore, lifestyle modification, both in transplant waiting list patients and after kidney transplantation, can reduce the risk of developing diabetes $(18,20)$.

In our study, $70(52.2 \%)$ patients with PTDM had a family history of diabetes. However, only $37.9 \%$ of nonPTDM mentioned it, and the difference between the two groups was significant. In multivariate analysis, there was a 2.2-fold increased risk of PTDM in kidney recipients with a family history of diabetes, and this association was significant. Previous studies have detected that a family history of diabetes increases up to seven times the risk of PTDM (19). In fact, people with a positive family history of diabetes have a higher genetic predisposition that may contribute to the development of PTDM.

The majority of our patients received kidneys from a living donor (70.6\%). The incidence of PTDM was higher in the deceased donor than the living donor (45.4\% versus $22.3 \%)$. In the deceased donor, the incidence of PTDM was 2.4 times that of the living. Various studies have shown that kidney transplantation from a deceased donor has been associated with a higher incidence of PTDM $(10,25)$. Since, patients who receive a kidney from a deceased donor usually need higher doses of immunosuppressive drugs, to prevent rejection.

Studies on hepatitis $\mathrm{C}$ have shown that the disease predisposes a person to hypoglycemia $(7,26)$. In our study, HCV was significantly associated with PTDM in 
multivariate analysis. Therefore, in kidney recipients with $\mathrm{HCV}$, the risk of PTDM was about 4-fold higher. This factor is so important because antiviral treatment of $\mathrm{HCV}$ in transplant patients can have a preventive effect on the incidence of diabetes and also improves glycemic control in the patient (7).

About $46 \%$ of people with PTDM and $31 \%$ of NonPTDM had history of CMV positive. In kidney recipients with CMV, the risk of PTDM was about 3-fold higher. Hjelmesaeth et al showed that CMV infection has been linked to type 1 diabetes and may also increase the incidence of PTDM (27).

According to the results, TG in the two groups of patients (PTDM versus Non-PTDM) was statistically significant. However, in multivariate analysis, the effect of this factor on the incidence of PTDM was very small and was reported at half a percent. Chakkera et al achieved similar findings (28).

Regarding the effects of drugs on the incidence of PTDM, our findings showed that kidney transplant patients who took tacrolimus had a higher incidence of developing PTDM. This significance was also confirmed in multivariate analysis, which is consistent with other studies $(7,18,29)$.

The findings of our study showed a significant relationship between the use of beta-blockers (whether selective or non-selective) and the incidence of PTDM. Its users were about 5.5-fold more likely to develop PTDM than those who do not. Messerli et al also showed that, taking beta-blockers in non-diabetics could increase the risk of developing diabetes(30). In the study by Gress et al, the incidence of diabetes in patients receiving betablocker was $28 \%$ higher than those who did not take the drug (31). Of course, it should be noted that the type of beta blocker also has a significant effect on its diabetogenicity. New beta-blockers do not have these side effects and are suitable drugs to control blood pressure in diabetic patients(32).

Some studies such as study of Van Laecke et al, showed that patients with magnesium levels less than $1.9 \mathrm{mg} /$ dL had a higher risk of PTDM (33). Hence, we decided to compare the magnesium levels of patients, which unfortunately could not be compared due to lack of sufficient information.

\section{Conclusion}

Post-transplant diabetes is an important complication of renal transplantation that appears to have a high incidence. Classification of risk factors and intervention to minimize their complications should be an integral part of transplant recipients' management. In this regard, the long-term consequences associated with this disease is minimized. Non-modifiable risk factors for development of PTDM are family history of diabetes, and deceased donor. Modifiable risk factors are TG, HCV and CMV infections, use of tacrolimus and beta blocker. In patients at risk for
PTDM, exposure to diabetogenic immunosuppressive drugs should be reduced carefully.

Limitations of the study

Limitations of our study were the lack of uric acid and magnesium levels in patients' records, the lack of an exact dose of corticosteroids, and the form and duration of smoking.

\section{Acknowledgements}

The authors would like to thank the personnel of Razi Clinical Research Development Center, the Vice Chancellor for Research of Guilan University of Medical Sciences, the staff of Razi Hospital and all patients who participated in the study for their valuable support and cooperation. The interpretation and reporting of these data are the responsibility of the authors.

\section{Authors' contribution}

ER, AT, AM and MKH were the principal investigators of the study. ER, AT, AM, EKL and MKH were included in preparing the concept and design. ML, BM and GM revisited the manuscript and critically evaluated the intellectual contents. All authors participated in preparing the final draft of the manuscript, revised the manuscript and critically evaluated the intellectual contents. All authors have read and approved the content of the manuscript and confirmed the accuracy or integrity of any part of the work.

\section{Conflicts of interest}

Authors have no conflicts of interest to declare.

\section{Ethical considerations}

Ethical issues (including plagiarism, data fabrication, double publication) have been completely observed by the authors.

\section{Funding/Support}

This study was supported by Guilan University of Medical Sciences (Grant \#1100).

\section{References}

1. Tonelli M, Wiebe N, Knoll G, Bello A, Browne S, Jadhav D, et al. Systematic review: kidney transplantation compared with dialysis in clinically relevant outcomes. Am J Transplant. 2011;11:2093-109. doi: 10.1111/j.1600-6143.2011.03686.x.

2. Au E, Wong G, Chapman JR. Cancer in kidney transplant recipients. Nat Rev Nephrol. 2018;14:508-20. doi: 10.1038/ s41581-018-0022-6.

3. Awan AA, Niu J, Pan JS, Erickson KF, Mandayam S, Winkelmayer WC, et al. Trends in the causes of death among kidney transplant recipients in the United States (1996-2014). Am J Nephrol. 2018;48:472-81. doi: 10.1159/000495081.

4. Bicalho PR, Requião-Moura LR, Arruda ÉF, Chinen R, Mello L, Bertocchi APF, et al. Long-term outcomes among kidney transplant recipients and after graft failure: a single-center 
cohort study in Brazil. Biomed Res Int. 2019;2019:7105084. doi: 10.1155/2019/7105084

5. Yates CJ, Fourlanos S, Hjelmesæth J, Colman PG, Cohney SJ. New-onset diabetes after kidney transplantationchanges and challenges. Am J Transplant. 2012;12:820-8. doi: 10.1111/j.1600-6143.2011.03855.x.

6. Cohen E, Korah M, Callender G, Belfort de Aguiar R, Haakinson D. Metabolic disorders with kidney transplant. Clin J Am Soc Nephrol. 2020;15(5):732-42. doi: 10.2215/ CJN.09310819.

7. Kasiske BL, Snyder JJ, Gilbertson D, Matas AJ. Diabetes mellitus after kidney transplantation in the United States. Am J Transplant. 2003;3:178-85. doi: 10.1034/j.16006143.2003.00010.x.

8. Sinangil A, Celik V, Barlas S, Koc Y, Basturk T, Sakaci T, et al. The incidence of new onset diabetes after transplantation and related factors: Single center experience. Nefrologia. 2017;37:181-8. doi: 10.1016/j.nefro.2016.11.022.

9. Sharif A, Hecking M, de Vries APJ, Porrini E, Hornum $\mathrm{M}$, Rasoul-Rockenschaub $\mathrm{S}$, et al. Proceedings from an international consensus meeting on posttransplantation diabetes mellitus: recommendations and future directions. Am J Transplant. 2014;14:1992-2000. doi: 10.1111/ajt.12850

10. Ahmed SH, Biddle K, Augustine T, Azmi S. PostTransplantation Diabetes Mellitus. Diabetes Ther. 2020;11:779-801. doi: 10.1007/s13300-020-00790-5

11. Chowdhury TA. Post-transplant diabetes mellitus. Clin Med (Lond). 2019;19:392-5. doi: 10.7861/clinmed.2019-0195.

12. Pham PTT, Pham P-MT, Pham SV, Pham PAT, Pham PCT. New onset diabetes after transplantation (NODAT): an overview. Diabetes Metab Syndr Obes. 2011;4:175-86. doi: 10.2147/DMSO.S19027

13. Gomes V, Ferreira F, Guerra J, Bugalho MJ. New-onset diabetes after kidney transplantation: Incidence and associated factors. World J Diabetes. 2018;9:132-7. doi: 10.4239/wjd.v9.i7.132

14. Langsford D, Dwyer K. Dysglycemia after renal transplantation: Definition, pathogenesis, outcomes and implications for management. World J Diabetes. 2015;6:1132-51. doi: 10.4239/ wjd.v6.i10.1132

15. Solhjoo M, Kumar SC. New Onset Diabetes After Transplant (NODAT). StatPearls Publishing; 2019.

16. Jahromi M, Al-Otaibi T, Othman N, Gheith O, Mahmoud T, Nair P, et al. Immunogenetics of new onset diabetes after transplantation in Kuwait. Diabetes Metab Syndr Obes. 2019;12:731-42. doi: 10.2147/DMSO.S195859

17. Palepu S, Prasad GR. New-onset diabetes mellitus after kidney transplantation: Current status and future directions. World J Diabetes. 2015;6:445. doi: 10.4239/wjd.v6.i3.445

18. Rodrigo E, Fernández-Fresnedo G, Valero R, Ruiz JC, Piñera C, Palomar R, et al. New-Onset Diabetes after Kidney Transplantation: Risk Factors. J Am Soc Nephrol. 2006;17:S291-S5. doi: 10.1681/ASN.2006080929

19. Sarno G, Muscogiuri G, De Rosa P. New-Onset Diabetes After Kidney Transplantation: Prevalence, Risk Factors, and Management. Transplantation. 2012;93:1189-95. doi: 10.1097/TP.0b013e31824db97d.

20. Cosio FG, Pesavento TE, Osei K, Henry ML, Ferguson RM. Post-transplant diabetes mellitus: increasing incidence in renal allograft recipients transplanted in recent years. Kidney Int.
2001;59:732-7. doi: 10.1046/j.1523-1755.2001.059002732.x.

21. Santos L, Rodrigo E, Piñera C, Quintella E, Ruiz JC, Fernández-Fresnedo G, et al. New-onset diabetes after transplantation: drug-related risk factors. Transplant Proc. 2012;44:2585-7. doi: 10.1016/j.transproceed.2012.09.053

22. Dedinska I, Laca L, Miklusica J, Ulianko J, Janek J, Galajda P, et al. Effect of smoking on development of new onset diabetes mellitus after transplantation (NODAT) of kidney. Acta Medica Martiniana. 2016;16(3):14. doi: 10.1515/acm-20160013

23. Numakura K, Satoh S, Tsuchiya N, Horikawa $\mathrm{Y}$, Inoue T, Kakinuma $\mathrm{H}$, et al. Clinical and genetic risk factors for posttransplant diabetes mellitus in adult renal transplant recipients treated with tacrolimus. Transplantation. 2005;80:1419-24. doi: 10.1097/01.tp.0000181142.82649.e3

24. Tuomilehto J, Lindström J, Eriksson JG, Valle TT, Hämäläinen $\mathrm{H}$, Ilanne-Parikka $\mathrm{P}$, et al. Prevention of type 2 diabetes mellitus by changes in lifestyle among subjects with impaired glucose tolerance. N Engl J Med. 2001;344:1343-50. doi: 10.1056/NEJM200105033441801

25. Lv C, Chen M, Xu M, Xu G, Zhang Y, He S, et al. Influencing factors of new-onset diabetes after a renal transplant and their effects on complications and survival rate. PLoS One. 2014;9:e99406. doi: 10.1371/journal.pone.0099406.

26. Bloom RD, Rao V, Weng F, Grossman RA, Cohen D, Mange KC. Association of hepatitis $C$ with posttransplant diabetes in renal transplant patients on tacrolimus. J Am Soc Nephrol. 2002;13:1374-80. doi: 10.1097/01.asn.0000012382.97168.e0

27. Hjelmesaeth J, Sagedal S, Hartmann A, Rollag H, Egeland T, Hagen M, et al. Asymptomatic cytomegalovirus infection is associated with increased risk of new-onset diabetes mellitus and impaired insulin release after renal transplantation. Diabetologia. 2004;47:1550-6. doi: 10.1007/s00125-0041499-z

28. Chakkera HA, Weil EJ, Swanson CM, Dueck AC, Heilman RL, Reddy KS, et al. Pretransplant risk score for newonset diabetes after kidney transplantation. Diabetes Care. 2011;34:2141-5. doi: 10.2337/dc11-0752

29. Agarwal DK, Singh U. Post Transplant Diabetes Mellitus in Renal Transplant Recipients. Apollo Medicine. 2008;5(4):33844.

30. Messerli FH, Bangalore S, Julius S. Risk/benefit assessment of beta-blockers and diuretics precludes their use for first-line therapy in hypertension. Circulation. 2008;117:2706-15. doi: 10.1161/CIRCULATIONAHA.107.695007

31. Gress TW, Nieto FJ, Shahar E, Wofford MR, Brancati FL. Hypertension and antihypertensive therapy as risk factors for type 2 diabetes mellitus. N Engl J Med. 2000;342(13):905-12. doi: 10.1056/NEJM200003303421301

32. Sarafidis P, Bakris G. Antihypertensive treatment with betablockers and the spectrum of glycaemic control. Journal of the Association of Physicians. 2006;99(7):431-6. doi: 10.1093/ qjmed/hcl059

33. Van Laecke S, Van Biesen W, Verbeke F, De Bacquer D, Peeters P, Vanholder R. Posttransplantation hypomagnesemia and its relation with immunosuppression as predictors of new-onset diabetes after transplantation. Am J Transplant. 2009;9(9):2140-9. doi: 10.1111/j.1600-6143.2009.02752.x

Copyright (c) 2021 The Author(s); Published by Nickan Research Institute. This is an open-access article distributed under the terms of the Creative Commons Attribution License (http://creativecommons.org/licenses/by/4.0), which permits unrestricted use, distribution, and reproduction in any medium, provided the original work is properly cited. 